Int. J. Electrochem. Sci., 13 (2018) 4020 - 4031

\title{
Preparation of Hierarchical Porous Carbon Based on Corn- Straw Carbon Nanofiber as an Efficient Electrode Material for Supercapacitors
}

Gaofeng Shi*, Yucan Dong, Guoying Wang , Xia Jiang, Chao Liu, Shiming Jia, Peng zhang, Hua Ma

School of Petrochemical Engineering, Lanzhou University of Technology, NO.287, Langongping Road, Lanzhou, Gansu, China

*E-mail: shigaofeng@lut.cn

doi: $10.20964 / 2018.11 .39$

Received: 4 June 2018 / Accepted: 30 August 2018 / Published: 10 March 2019

Pure PAN and corn-straw carbon mixed nanofibers were prepared by electrospinning. Using a novel method of $\mathrm{KOH}$ solid-state activation of nanofibers got hierarchical porous carbon material. The surface area and total pore volume of HPC were $2192.73 \mathrm{~m}^{2} \cdot \mathrm{g}^{-1}$ and $1.08 \mathrm{~cm}^{3} \cdot \mathrm{g}^{-1}$, and with an excellent specific capacitance of $376.5 \mathrm{~F} \cdot \mathrm{g}^{-1}$ at a current density of $0.5 \mathrm{~A} \cdot \mathrm{g}^{-1}$, remaining a capacitance retention of $94.18 \%$ after 5000 cycles at the current density of $2 \mathrm{~A} \cdot \mathrm{g}^{-1}$. This new material has excellent electrochemical performance and can be used as an electrode material for supercapacitors.

Keywords: Electrospinning method; hierarchical porous carbon; electrode materials; capacitive performance

\section{$\underline{\text { FULL TEXT }}$}

(C) 2018 The Authors. Published by ESG (www.electrochemsci.org). This article is an open access article distributed under the terms and conditions of the Creative Commons Attribution license (http://creativecommons.org/licenses/by/4.0/). 